\title{
RISK ASSESSMENT METHODOLOGIES TO SAFEGUARD HISTORIC URBAN AREAS FROM THE EFFECTS OF CLIMATE CHANGE
}

\author{
LAURA QUESADA-GANUZA ${ }^{1 *}$, LEIRE GARMENDIA ${ }^{1}$, EDUARDO ROJÍ $^{1}$, \\ IRANTZU ÁLVAREZ ${ }^{2}$, ESTIBALIZ BRIZ ${ }^{1}$, MARTA OLAZABAL ${ }^{3}$ \\ ${ }^{1}$ University of the Basque Country UPV/EHU, School of Engineering in Bilbao, Mechanical \\ Engineering Department, \\ Plaza Ingeniero Torres Quevedo s/n (48013) Bilbao. Spain. \\ e-mail: \{laura.quesada*, leire.garmendia, eduardo.roji, estibaliz.briz\}@ehu.eus, $\left({ }^{*}\right.$ corresponding \\ author) \\ ${ }^{2}$ University of the Basque Country UPV/EHU, School of Engineering in Bilbao, Department of \\ Graphic Design and Engineering Projects, Rafael Moreno "Pitxitxi", (48013) Bilbao. Spain \\ email: Irantzu.alvarez@ehu.eus \\ ${ }^{3}$ Basque Centre for Climate Change (BC3), Sede Building 1, 1st floor \\ Scientific Campus of the University of the Basque Country, \\ (48940) Leioa. Spain \\ email: marta.olazabal@bc3research.org
}

Keywords: Historic Urban Areas; Climate Change; Risk Assessment; Vulnerability Assessment; Key Performance Indicators

\begin{abstract}
A systematic and critical review of the existing literature on climate-change riskassessment methodologies for historic urban areas is presented, in view of the increasing likelihood of extreme weather events. Key performance indicators are identified for use in future risk assessment methodologies that address both the elements of historic urban areas as a system and the potential impact of prolonged heat waves. To do so, a systematic search of the existing literature on Web of Science and Scopus was conducted, with the aim of identifying and characterizing existing methodologies on vulnerability and risk assessment for cultural heritage exposed to the effects of a changing climate. The main characteristics of the methodologies that need to be addressed in the near future and key knowledge gaps were identified, among them, the lack of holistic heat-wave risk-assessment methodologies for historic urban areas.
\end{abstract}

\section{INTRODUCTION}

Given the increasing number of extreme weather events over recent decades, the debate over climate change in the scientific community has intensified. Global warming has increased over the past four decades, so much so that the 21 st century is now the warmest on record according to the reports from the World Meteorological Organization (WMO)[1]. This increase in global 
mean temperatures mainly due to anthropogenic activity adds to the risk of extreme events, such as heavy rains, heat waves and floods [2].

Over half of the global population now resides in urban areas [3] and maximum temperature rises are recorded within urban centers and their areas of influence [2], as the global population is inexorably drawn towards cities. The most recent special report from the Intergovernmental Panel on Climate Change (IPCC) highlighted urban areas and infrastructure as a system that is among others in major need of transformation, in order to ensure a resilient future. The negative effects of unrelenting global warming and the consequences of extreme weather events are significantly affecting the health of urban residents, and their assets, wellbeing and livelihoods $[2,4]$.

Even if cities suffer the same climatic conditions as the surroundings countryside, specific events within urban settings result in microclimates and heat-island effects. Low permeability of the soil, higher population densities, higher concentrations of productive activities, and urban planning define urban areas and differentiate their relationship with and response to the changing climate. Urban areas are therefore complex systems formed of several interrelated layers that require specific approaches for assessing their exposure to climate change. Even though it is not frequently considered in their assessment, cultural heritage represents an intrinsic layer within a city. The specific characteristics of a historic city center or historic urban area are of special relevance as they are the source of urban identity and an important asset for the economic sector. The specific vulnerabilities of historic areas to changes in weather patterns [5] are not only because of physical impacts on the built structures, but also other consequences that are very relevant to tourism, and the dis Over the past decace, organizations such as cultural heritage risk assessmen Work Plan for Culture 2019-2022 including a topic on adaptation to climate change [8,9]. The
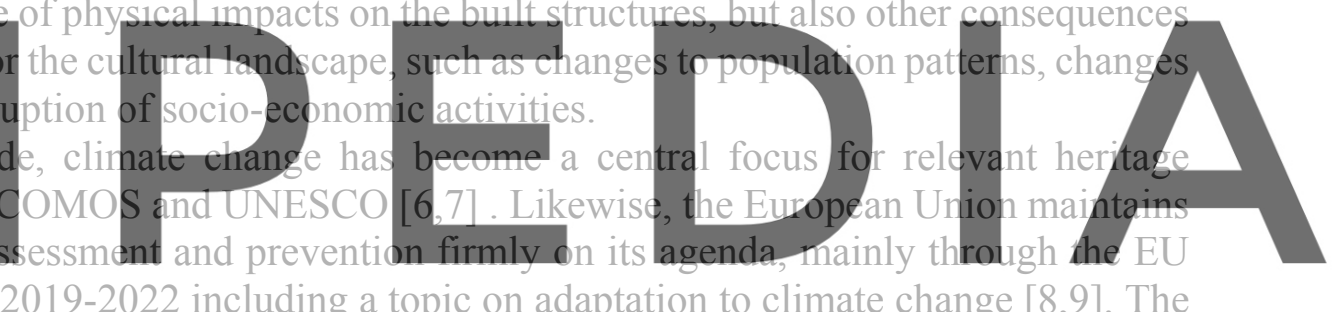

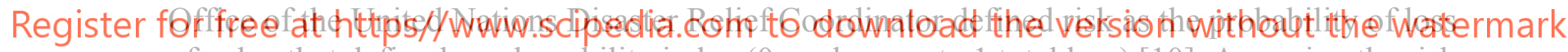
of value that defined a vulnerability index (0 no damage to 1 total loss) [10]. Assessing the risk that historic urban areas face with regard to climate change is therefore at the heart of the policy discussion and a very important research area, if we are to understand how the future resilience of cities may be increased. It means adding the layer of cultural heritage, and the specific characteristics of the historic urban grid to the assessment of urban areas.

The objective of this paper is twofold. The first objective is to perform a critical review of the current state of the art of climate-change risk-assessment methodologies for historic areas. The second objective is to respond to the research gap that has been identified in this field, by proposing key performance indicators that should be included in risk assessment methodologies to develop a holistic approach for the risk assessment of historic urban areas that are exposed to heat waves.

\section{CRITICAL REVIEW ON CLIMATE CHANGE RISK ASSESMENT METHODOLOGIES}

In this section, the results are presented of a systematic search of the literature, in order to conduct a critical review of climate-change risk-assessment methodologies for historic areas 
[11], as well as to determine any relevant knowledge gaps. The research question [12] is therefore as follows. Which risk or vulnerability assessment methodologies are related to the effects of climate change on historic areas? A critical review of those methodologies [13] will then assess the main characteristics of the methodologies, mainly the hazards that are addressed and the risk elements (hazard, exposure, vulnerability) under consideration, including which aspect of the urban system they assess, with the understanding that an urban system is for our purposes an historic urban area.

The risk elements under analysis were derived from the IPCC approach that is the most widely used framework [2]. Risk was defined as a "probability or likelihood of occurrence of hazardous events or trends multiplied by the impacts if these events or trends occur" Moreover, the term impact is defined in relation to "the effects on natural and human systems of extreme weather and climate events and of climate change. Impacts generally refer to effects on lives, livelihoods, health, ecosystems, economies, societies, cultures, services, and infrastructure due to the interaction of climate changes or hazardous climate events occurring within a specific time period and the vulnerability of an exposed society or system" [2]. We can therefore conclude from these definitions that risk is characterized as an outcome of the interaction between hazard, vulnerability (the combination of an assets sensitivity to the hazard and its lack of capacity to cope with its adverse effects) and exposure (related to the location of the asset). It is therefore essential to note that an asset may be exposed but not vulnerable, although there must be a likelihood of its exposure to the event for it to be vulnerable

Based on the Fifth
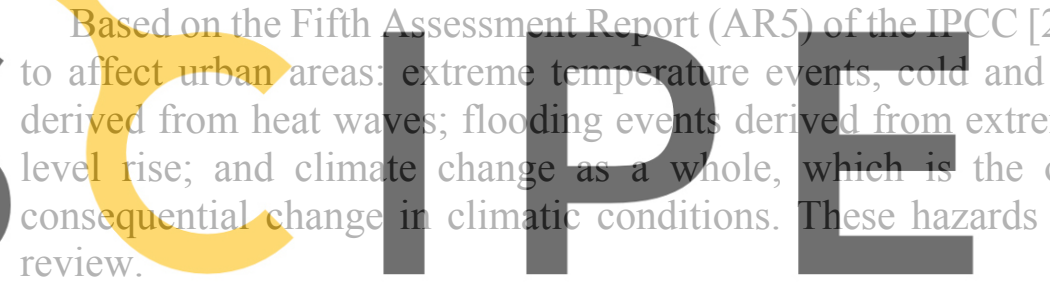

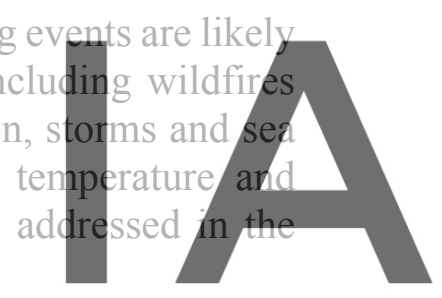

The keywords for the search were selected with reference to the research question and the

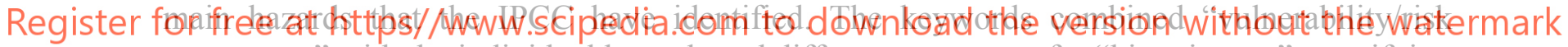
assessment" with the individual hazards and different synonyms for "historic area", specifying the root word of each keyword with its possible variations. The Web of Science and Scopus database search settings included title, keywords and abstract. A total of 616 results were returned on both platforms with all of the different combinations of keywords. A first filtration consisted of reading the title, and selecting papers related with the subject. This step was repeated for every search and on both platforms. Many of the search results from both databases were duplicated in the different searches, so the papers were screened and then unified to determine their eligibility in the next step. To do so, the abstract of each paper was individually reviewed to determine whether a risk assessment methodology or a climate change related hazard and its impact on each historic urban area was actually defined in the paper. Subsequently, a final full text analysis of the thirty-four articles remaining after the initial screening was conducted, in which some were excluded after a thorough final re-reading. In all, twenty-nine methodologies were identified and then studied (Figure 1). The selected papers were fully reviewed and classified depending on the hazard addressed and its associated aspects of risk (hazard, exposure, vulnerability). 


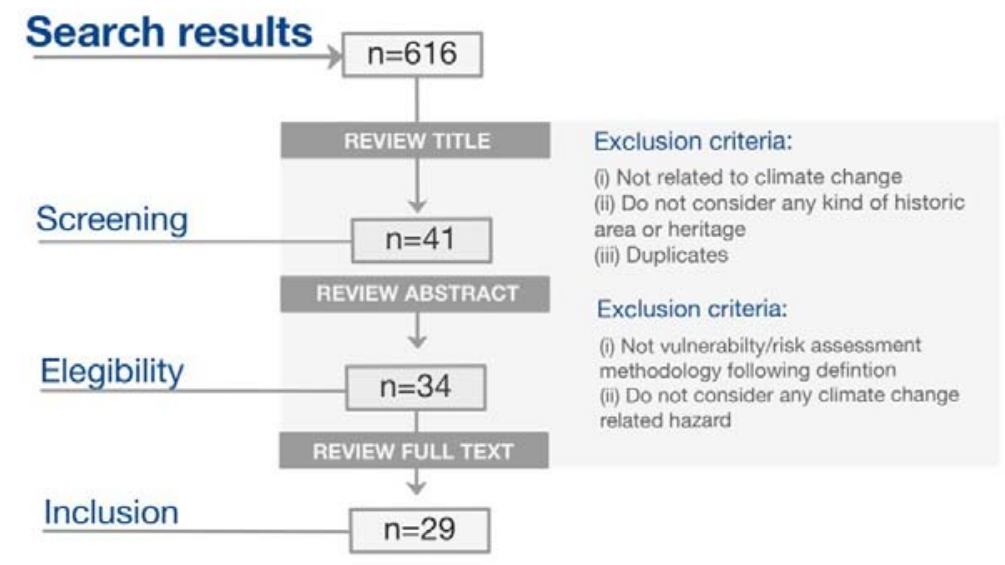

Figure 1: Literature search and evaluation for inclusion in the critical review (adapted from [12]).

\subsection{Risk aspects and dimensions within the methodologies}

The review of the twenty-nine methodologies served to determine the aspects of risk (hazard, exposure, vulnerability) that they were designed to consider and distinguishing between social, economic, cultural, governance (services and resources) and physical dimensions (gathering tangible characteristics of all infrastructure, elements and buildings). It should be noted that risk assessment is evaluated that both hazard and Hence, the results nay likelihood and severity; that continue to assess

As figure 2 shows, hazard 1ikelihood and
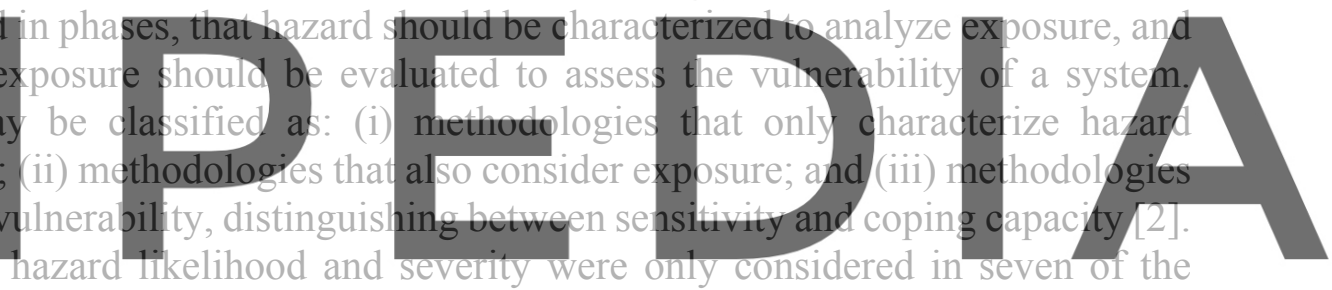

twenty-nine methodologies and the exposure of the elements was only also assessed in one.

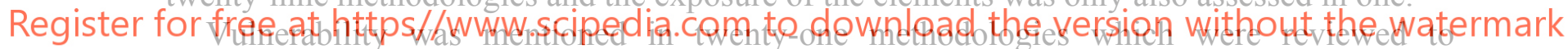

determine whether sensitivity indicators and/or coping capacity indicators were also mentioned

in them. Sensitivity was considered in almost half of the methodologies, though it was only acknowledged as such in a few studies and was referred to as vulnerability in the others. Taking into consideration the aforementioned categories and with regard to the vulnerability aspects, nineteen studies were focused on physical sensitivity, only eight of which included other aspects. Among the methodologies with a focus on physical vulnerability, the vulnerability of buildings to flooding was considered in eight and the physical vulnerability of assets to general climatic change was considered in four of them. The remaining two methodologies assessed vulnerability without contemplating physical vulnerability, placing their focus on governance vulnerability and the adaptive capacity [14] and their social coping capacity [15]. Socioeconomic vulnerability was also considered in some methodologies that addressed the coping capacity of inhabitants facing the hazard. Cultural value was only considered in several studies by A. Gandini [16,17,18] and in one methodology [19], all addressing flooding. 


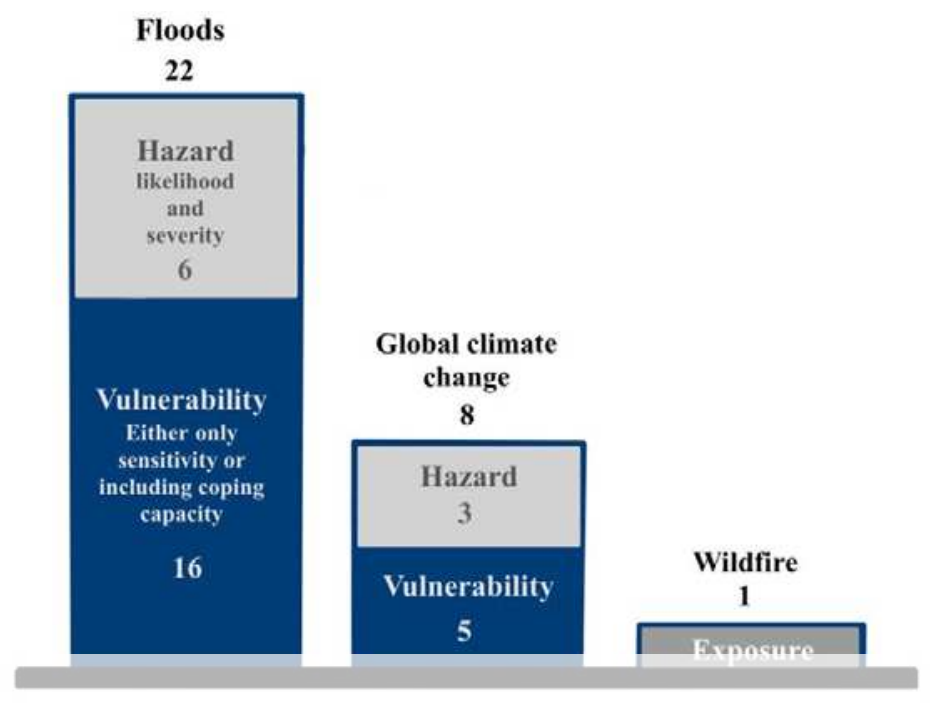

Figure 2: Overview of the results of the review.

\subsection{Hazards}

Figure 3 presents the results of the critical review classified by the hazard that is addressed. In the literature flooding that is either due to extreme precipitation or to sea-levelise is one of the most frequently analyzed hazards. It was considered in twenty-two out of the twenty-nine methodologies. Flooding toggther with other hazards was considered in three $\mathrm{n}$ methodologies $[20,21,22]$ and nineteen methodologies focused

climatic change caused by climate change was considered as twenty-nine methodologies in the review. Wildfires were methodology [23]. Cold and heat waves were therefore not considered as hazards in any of the

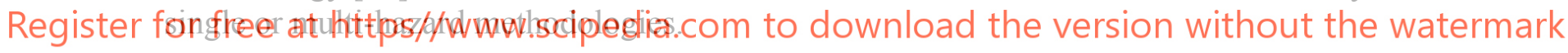

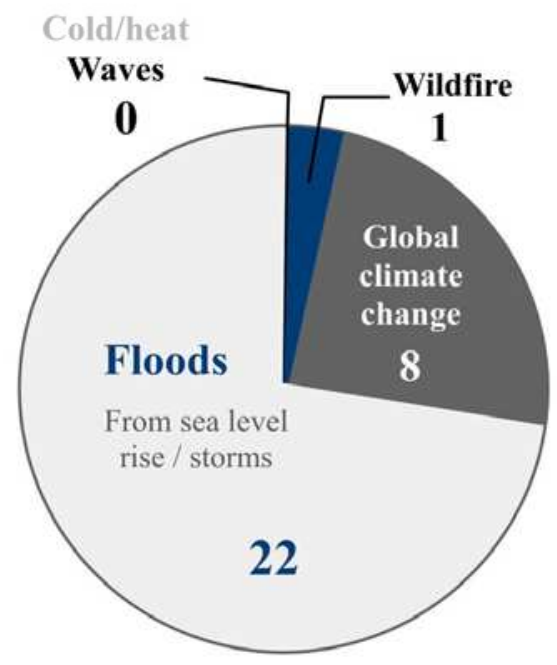

Figure 3: Number of risk assessment methodologies classified by type of hazard. 


\subsection{Outcomes of the critical review}

Starting with the hazards and the extreme events related to climate change events, the conclusions were clear, in so far as they determined that a large body of the literature addressed flooding, from either sea-level rise or storms, and a considerable number of studies addressed the general change in climatic conditions. In contrast, such hazards as cold and heat waves were not present in the methodologies found in the review.

As explained in the introduction, the vulnerability of urban environments is frequently linked in the literature to their socio-economic and physical conditions, such as geographical position, materials, urban plot, and morphology, wealth and governance system etc. [24]. These characteristics will determine the severity of the resulting impacts when considering climate change and consequent extreme events. In the case of historic urban areas, the review revealed a sharp focus on the physical vulnerability of the built environment while the vulnerabilities of other aspects of the system were overlooked. The effects of climate change on cultural diversity and socio-cultural interactions; and impacts such as the loss of the sense of community, traditional knowledge, cultural identity and natural and socio-economic systems have previously been documented elsewhere $[2,6,25]$, but few studies have considered climate impacts on cultural heritage through a holistic approach [26].

A higher frequency of heat waves of lengthier duration and higher intensity will occur according to current predictions at least once a year towards the end of the present century [27]. The high temperatures reached during heat waves are often exacerbated due to Urban Heat Island (UHI) effects [28] found in urban and suburban are rather than in outlying rurd
surroundings. The ongoing effects of heat waves include consecuences for human health and
mortality and significant environmental and economic impacts [29]. These impacts are even
more pronounced in urban areas with high population densities such as historic denters, yhich
will therefore be very vulnerable to extreme temperature events. Thus, assessing this type of
event is crucial, and, as seen in this review, there is a relevant need for risk-assessment methodologies for historic areas that address heat waves

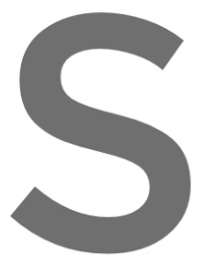
for free at https//www.scipedia.com to downloa

\section{PRELIMINARY PROPOSAL FOR KEY PERFORMANCE INDICATORS}

As demonstrated, holistic risk assessment methodologies to safeguard historic urban areas from heat waves are needed. In a holistic framework, social, economic, cultural, governance and physical dimensions should be considered and specific parameters or indicators that support the assessment of their individual risk should be determined. Individual and composite indicators are the foundation for vulnerability and risk assessment and are among the most common tools used to generate information on non-measurable conditions and to compare differently measured data, by synthesizing complex measurements into a single number [30].

Even if heat waves are characterized differently depending on the climate of the region, the WMO guidance on heat-health warning (WMO-No.1142) defined heatwaves as periods of unusually hot and dry or hot and humid weather that can extend over at least two to three days and can have a discernible impact on human activities [31]. The main indicators for the characterization of heat waves are therefore temperature and relative humidity; with levels of relative humidity defining whether it is a dry or a humid heat wave [32]. Consequently, exposure and vulnerability indicators must be derived from the cause-effect relationship between high heat, and low or high humidity and the elements that comprise the system of an 
historic urban area; including additional exposure variables.

Studies on UHI effects have shown that the morphological layout of an urban area that affects shading and ventilation, combined with the technical characteristics of urban elements and both the type and the distribution of green spaces are the main factors influencing its intensity [33]. Urban geometry and materials influence the wind flow, energy absorption, and surface reflectance properties that emit long wave radiation back into the atmosphere [28], which in turn condition the UHI effect.

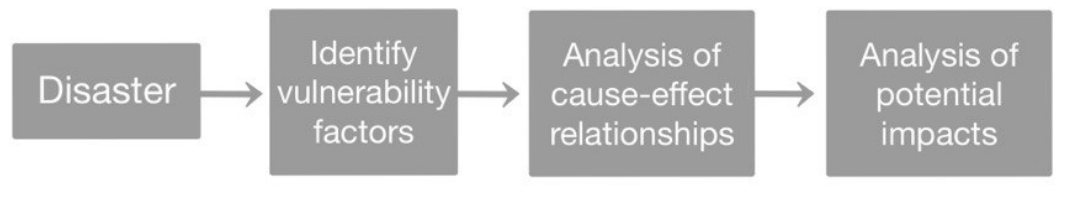

Figure 4. Develonment of indicators (Adanted from [34])

If we are to define the elements that comprise historic urban areas, the system needs to be addressed from two perspectives: as an urban system, and as an historic area. The indicators have been gathered revising key documents that, either from an urban perspective, wellness of the population or the weathering of historic materials, address evaluative aspects. For the identification of the indicators, we have conceptually followed the approach in Figure 4. The historic urban area is considered as a combination of an urban system [35] with the addition of

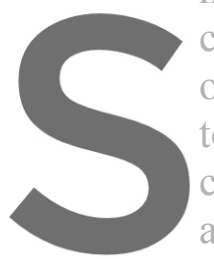
carriers of significande of the urban system. So to be assessed, as seen cultural, governance ( all infrastructures, elem
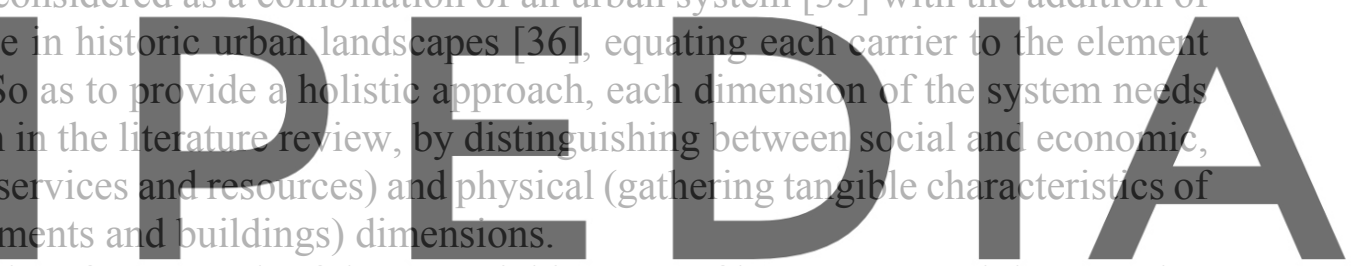

The indicators are therefore a result of the potential impacts of heat waves and the UHI that

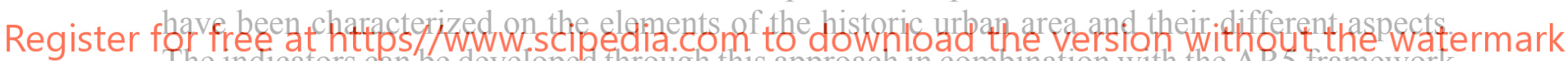
The indicators can be developed through this approach in combination with the ARS framework

from the IPCC. Therefore, the indicators proposed follow this order; hazard characterization, exposure, and vulnerability, divided between sensitivity and coping capacity.

With regard to the hazard indicators, the above-mentioned characterization of heat waves is based on the main factors: temperature, humidity, sun exposure and wind. The different ways that humidity variations can affect traditional materials means that additional indicators are humidity cycles and shocks [37].

The exposure is divided into the two main physical components of urban areas, buildings and open spaces. The exposure of a building is mainly defined by its exposure to sunlight, calculated in terms of hourly exposure of the envelope to solar radiation, depending on the orientation of the building and considering the different angles of façade exposure and the possible shading from the surrounding buildings. Meanwhile open spaces require the addition of UHI indicators, such as the Sky View Factor that determines the proportion of an urban space with heat-storage capabilities [38] that can contribute to the 'urban canyon' effect [28]. Another relevant indicator for open spaces is related to the presence of green elements that can be assessed using the Normalized Difference Vegetation Index (NDVI), which is based on the quantification of vegetation through the analysis of satellite imagery. Other location-dependent 
urban characteristics that have been linked to interactions with heat in the literature are tropospheric Ozone (O3) levels and acoustic pollution. There is abundant research to show that ozone levels can increase under specific meteorological conditions such as high temperature, intense solar radiations, and long sunshine hours, all characteristics of heatwaves [39], which can have consequences for the health of urban populations [40]. With regard to acoustic pollution, studies have shown that people living in areas with high noise levels tend to ventilate their homes less, which increases heat storage within the building [41].

The sensitivity indicators are divided into three components: social sensitivity, buildings, and open spaces; with the last two considering physical, economic, and cultural dimensions. Social sensitivity is dependent on the characteristics of the population, both because of age groups and socioeconomic data, as well as population density. The sensitivity indicators of the buildings are in turn divided into three main dimensions: physical, economic, and cultural. Physical sensitivity is mainly based on the possible weathering of sensitive traditional materials under heat-wave conditions [37] and the thermal characteristics of the materials, such as their albedo and thermal diffusivity rates. Economic aspects are based on the use of a building, either because of its use for production, or as housing, or because of its touristic value. The main indicators of cultural sensitivity are the symbolism of the building either for collective memories, or rituals or traditions. With regard to the sensitivity of public spaces, the indicators are divided into the same three main categories mentioned above in relation to the buildings, as well as the solar reflectance of the materials in terms of their physical sensitivity.

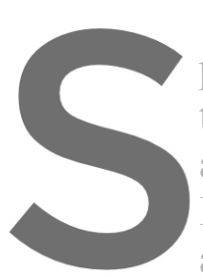

As with the sensitivity
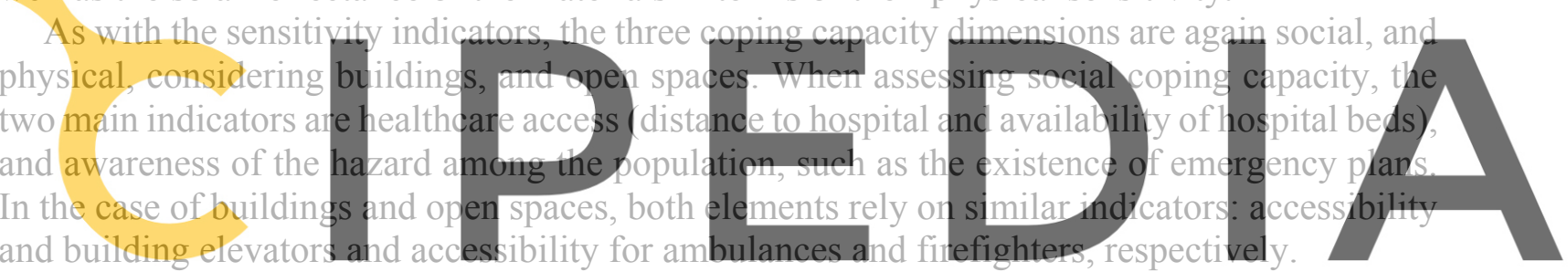

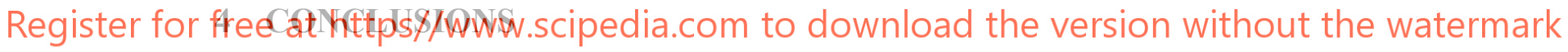

The risk assessment indicators in the second part of this paper have been proposed to address the knowledge gap that has been identified in the first part; namely, the scarcity of heat-wave risk-assessment methodologies for historic urban areas. The analysis of the urban system or urban area with an historic layer is flexible and could be adapted to any other urban area or district. The indicators have been developed with data availability in mind, ensuring repeatability and easy comparison of results.

A future goal following this study will be to produce a complete risk assessment methodology for historic urban areas, with an output based on an accessible and easily replicated Geographical Information System (GIS) model.

Acknowledgements. The authors wish to acknowledge the funding from the European Commission through the SHELTER project (GA 821282) and the University of the Basque Country UPV/EHU (PPGA20_26) as well as the support of research groups IT1314-19 of the Basque Government and GIU19/029 of the University of the Basque Country UPV/EHU. MO would like to acknowledge the funding received by BC3 under the Spanish State Research Agency through Maria de Maeztu program (MDM-2017-0714) and under the Basque 
Government BERC 2018-2021 program.

\section{REFERENCES}

[1.] WMO. WMO Statement on the Status of the Global Climate in 2012 (2013). http://www.wmo.int/pages/mediacentre/press_releases/documents/WMO_1108_EN_W eb_000.pdf.

[2.] IPCC. Climate Change 2014: Synthesis Report. Contribution of Working Groups I, II and III to the Fifth Assessment Report of the Intergovernmental Panel on Climate Change [Core Writing Team, R.K. Pachauri and L.A. Meyer (eds.)]. IPCC, Geneva, Switzerland, 151 pp. (2014)

[3.] UN-Habitat. World Cities Report 2016: Urbanization and Development - Emerging Futures, (2016). https://unhabitat.org/world-cities-report.

[4.] EEA. Climate Change, Impacts and Vulnerability in Europe 2016: An Indicator-Based Report, (2017). https://doi.org/10.2800/534806.

[5.] Sabbioni, C., Brimblecombe, P., Cassar, M., and Noah's Ark (Project). The atlas of climate change impact on European cultural heritage: scientific analysis and management strategies. EC cultural heritage research series; n. 19. London; SE.: Anthem, (2010).

Cassar, M., Young, C., Weighell, T., ICCROM, ICOMOS, Sheppard, D., Bomhard, B.,

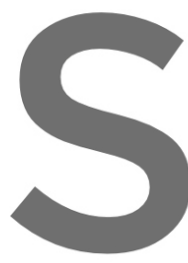

Rosabal, P., and and Managing th

States Parties to

Colette, (2007).

[7.] Markham, A., Brabec,

Future of Our $\mathrm{P}$ -
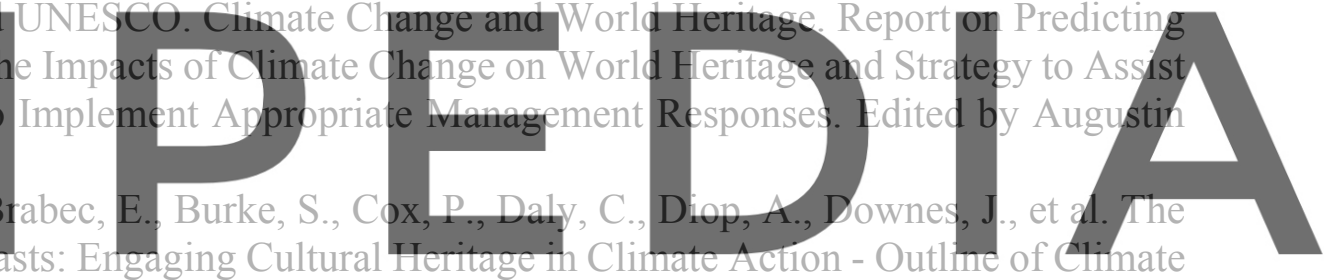

Change and Cultural Heritage, (2019)

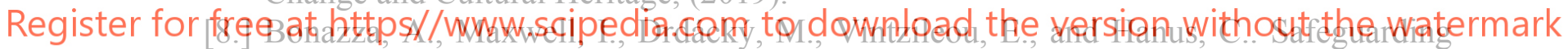

Cultural Heritage from Natural and Man-Made Disasters: A Comparative Analysis of

Risk Management in the EU. Luxembourg: Publications Office of the European Union, (2018).

[9.] Council of Europe. Recommendation CM/Rec(2018)3 of the Committee of Ministers to Member States on Cultural Heritage Facing Climate Change: Increasing Resilience and Promoting Adaptation, (2018).

[10.] UNDRO. Natural Disasters and Vulnerability Analysis : Report of Expert Group Meeting, 9-12 July 1979. Geneva: Office of the United Nations Disaster Relief Coordinator, (1980).

[11.] Berrang-Ford, L., Pearce, T., and Ford, J.D.. Systematic Review Approaches for Climate Change Adaptation Research. Regional Environmental Change 15, no. 5 (2015): 755-69. https://doi.org/10.1007/s10113-014-0708-7.

[12.] Xiao, Y., and Watson, M. Guidance on Conducting a Systematic Literature Review. Journal of Planning Education and Research 39, no. 1 (2017): 93-112. https://doi.org/10.1177/0739456X17723971.

[13.] Grant, M. J., and Booth, A. A Typology of Reviews: An Analysis of 14 Review Types 
and Associated Methodologies. Health Information and Libraries Journal 26, no. 2 (2009): 91-108. https://doi.org/10.1111/j.1471-1842.2009.00848.x.

[14.] Sesana, E., Gagnon, A. S., Bertolin, C., and Hughes, J. Adapting Cultural Heritage to Climate Change Risks: Perspectives of Cultural Heritage Experts in Europe. $\begin{array}{llllll}\text { Geosciences } & \text { (Switzerland) } & 8 & \text { no. } & 8 & \text { (2018): }\end{array}$ https://doi.org/10.3390/geosciences8080305.

[15.] Bernardini, G., Postacchini, M., Quagliarini, E., D’Orazio, M., and Brocchini, M. Flooding Pedestrians' Evacuation in Historical Urban Scenario: A Tool for Risk Assessment Including Human Behaviors. RILEM Bookseries 18 (2019): 1152-61. https://doi.org/10.1007/978-3-319-99441-3_124

[16.] Gandini, A., Garmendia, L., Prieto, I., Álvarez, I., and San-José, J.-T. A Holistic and Multi-Stakeholder Methodology for Vulnerability Assessment of Cities to Flooding and Extreme Precipitation Events. Sustainable Cities and Society 63 (2020). https://doi.org/10.1016/j.scs.2020.102437

[17.] Gandini, A., Prieto, I., Garmendia, L., San-José, J.-T., and Egusquiza, A.. Adaptation to Flooding Events through Vulnerability Mapping in Historic Urban Areas. In International Archives of the Photogrammetry, Remote Sensing and Spatial Information Sciences - ISPRS Archives, 42:221-26, (2018). https://doi.org/10.5194/isprs-archivesXLII-3-W4-221-2018

[18.] Gandini, A., Garmendia, L., and San Mateos, R.. Towards Sustainable Historic Cities:
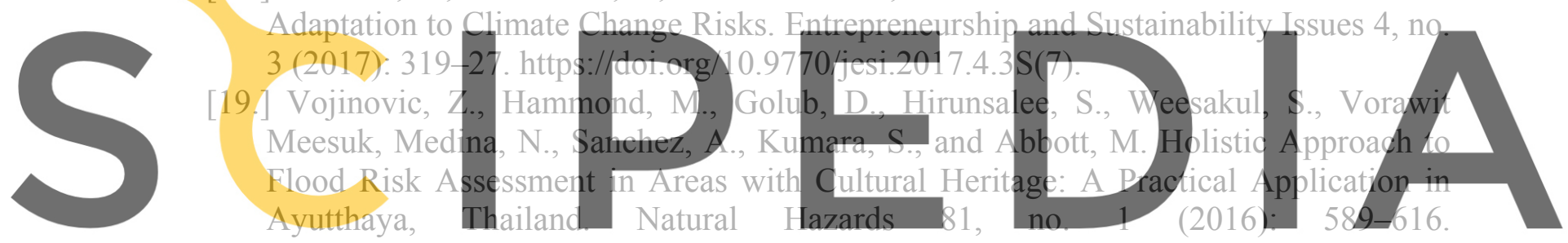
https://doi.org/10.1007/s11069-015-2098-7

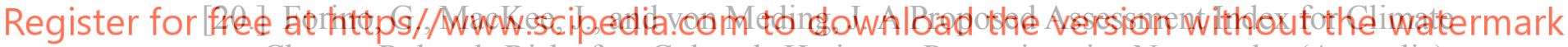
Change-Related Risk for Cultural Heritage Protection in Newcastle (Australia). International Journal of Disaster Risk Reduction 19 (2016): 235-48. https://doi.org/10.1016/j.ijdrr.2016.09.003.

[21.] Kotova, L., Jacob, D., Leissner, J., Mathis, M., and Mikolajewicz, U. Climate Information for the Preservation of Cultural Heritage: Needs and Challenges. Communications in Computer and Information Science 961 (2019): 353-59. https://doi.org/10.1007/978-3-030-12957-6_25

[22.] Ravankhah, M., Chmutina, K., Schmidt, M., and Bosher, L. Integration of Cultural Heritage into Disaster Risk Management: Challenges and Opportunities for Increased Disaster Resilience. In Going Beyond. Heritage Studies No. 2, edited by M.-T. Albert et al. (eds.), 307-21. Springer International Publishing AG, (2017). https://doi.org/10.1007/978-3-319-57165-2.

[23.] Mallinis, G., Mitsopoulos, I., Beltran, E., and Goldammer, J. G.. Assessing Wildfire Risk in Cultural Heritage Properties Using High Spatial and Temporal Resolution Satellite Imagery and Spatially Explicit Fire Simulations: The Case of Holy Mount Athos, Greece. FORESTS 7, no. 2 (2016). https://doi.org/10.3390/f7020046.

[24.] Georgi, B., Swart, R., Marinova, N., Hove, B., Jacobs, C., Klostermann, J., et al. Urban 
Adaptation to Climate Change in Europe Challenges and Opportunities for Cities Together with Supportive National and European Policies, Rep. No. 2/2012, (2012). https://doi.org/10.2800/41895.

[25.] Adger, W. N., Barnett, J., Brown, K., Marshall, N., and O'Brien, K. Cultural Dimensions of Climate Change Impacts and Adaptation. Nature Climate Change 3, no. 2 (2013): 112-17. https://doi.org/10.1038/nclimate1666.

[26.] Gandini, A., Egusquiza, A., Garmendia, L., and San-Jose, J.-T. Vulnerability Assessment of Cultural Heritage Sites towards Flooding Events. In Florence Heri-Tech - The Future Of Heritage Science And Technologies, Vol. 364. IOP Conference SeriesMaterials Science and Engineering. Dirac House, Temple Back, Bristol Bs1 6be, England: Iop Publishing Ltd, (2018). https://doi.org/10.1088/1757-899X/364/1/012028

[27.] Lemonsu, A., Viguié V., Daniel M., and Masson V. Vulnerability to Heat Waves: Impact of Urban Expansion Scenarios on Urban Heat Island and Heat Stress in Paris (France). Urban Climate 14 (2015): 586-605. https://doi.org/10.1016/j.uclim.2015.10.007.

[28.] Gartland, L. Heat islands : understanding and mitigating heat in urban areas. London SE - xiii, 192 p. : il.: Earthscan, (2010).

[29.] Zuo, J., Pullen S., Palmer, J., Bennetts, H., Chileshe, N., and Ma, T. Impacts of Heat Waves and Corresponding Measures: A Review. Journal of Cleaner Production 92 (2015): 1-12. https://doi.org/10.1016/j.jclepro.2014.12.078.

[30.] Kalisch, A., y Satapath S., Porsché I., r Rolke D., Bhatt S., Tomar S., and Nair S. A Framework for Climate Change Vulnerability Assessments | CCARDESA, (2014).

[31.] World Meteorological Organization. Guidelines on the Defintion and Monitoring of Extreme Weather and Climate Events, (2018). https://doi.org/10.1109/CSCI.2015.171.

[32.] Chen, X., Li, N., Liu J., Zhang Z., and Liu Y. Global Heat Wave Hazard Considering Humidity Effects during the 21st Century. International Journal of Environmental Research and Public Health 16, no. 9 (2019). https://doi.org/10.3390/ijerph16091513.

[33.] Li, D., and Bou-Zeid, E. Synergistic Interactions between Urban Heat Islands and Heat Waves: The Impact in Cities Is Larger than the Sum of Its Parts. Journal of Applied Meteorology and Climatology 52, no. 9 (2013): 2051-64. https://doi.org/10.1175/JAMC-D-13-02.1.

[34.] UNESCO. Managing Disaster Risks for World Heritage. Paris: UNESCO World Heritage Center, (2010). https://whc.unesco.org/en/managing-disaster-risks/.

[35.] Rus, K., Kilar V., and Koren, D. Resilience Assessment of Complex Urban Systems to Natural Disasters: A New Literature Review. International Journal of Disaster Risk Reduction 31, no. March (2018): 311-30. https://doi.org/10.1016/j.ijdrr.2018.05.015.

[36.] Araoz, G. F. World-Heritage and Defining Historic Protecting Urban Landscapes : Authenticity. APT Bulletin: Journal of Preservation Technology 2-3, no. 39 (2008): 3337.

[37.] Brimblecombe, P., Grossi C. M., and Harris I. Climate Change Critical to Cultural Heritage. Survival and Sustainability, (2011), 195-205. https://doi.org/10.1007/978-3540-95991-5.

[38.] Dirksen, M., Ronda R. J., Theeuwes N. E., and Pagani G. A. Sky View Factor Calculations and Its Application in Urban Heat Island Studies. Urban Climate 30 (2019): 100498. https://doi.org/10.1016/j.uclim.2019.100498. 
[39.] Pyrgou, A., Hadjinicolaou P., and Santamouris M. Enhanced Near-Surface Ozone under Heatwave Conditions in a Mediterranean Island. Scientific Reports 8, no. 1 (2018): 9191. https://doi.org/10.1038/s41598-018-27590-z.

[40.] Stedman, J. R. The Predicted Number of Air Pollution Related Deaths in the UK during the August 2003 Heatwave. Atmospheric Environment 38, no. 8 (2004): 108790. https://doi.org/10.1016/j.atmosenv.2003.11.011.

[41.] Núñez Peiró, M., Sánchez, C., Sanz-Fernández, A., Heredia, M., López-Bueno, J., Neila, J., C. Linares, Díaz, J., and Muñoz, G. Exposure and Vulnerability towards Summer Energy Poverty in the City of Madrid: A Gender Perspective, In Press, (2020). 